\title{
Commentary: Are we there yet? Long-term ventricular assist device therapy in pediatric heart centers
}

\author{
Karthik Thangappan, MD, and David L. S. Morales, MD
}

\footnotetext{
From the Department of Cardiovascular Surgery, Cincinnati Children's Hospital Medical Center, Cincinnati, Ohio.

Disclosures: Dr Morales is a consultant and instructor for Berlin Heart, Inc; a proctor and consultant for SynCardia, Inc; a national primary investigator for the 50/50cc SynCardia Total Artificial Heart Food and Drug Administration trial; a consultant for Medtronic Inc (HeartWare Division); and a consultant for Abbott Medical Inc (Thoratec Division). Dr Thangappan has nothing to disclose with regard to commercial support. Received for publication Aug 2, 2019; revisions received Aug 2, 2019; accepted for publication Aug 2, 2019. Address for reprints: David L.S. Morales, MD, Congenital Heart Surgery-Heart Institute, Quality and OutcomesDepartment of Surgery, Cincinnati Children's Hospital Medical Center, Department of Cardiovascular Surgery, 3333 Burnet Ave, MLC 2004, Cincinnati, OH 45229 (E-mail: David.Morales@cchmc.org).

J Thorac Cardiovasc Surg 2019;158:1442-3

$0022-5223 / \$ 36.00$

Copyright $($ c 2019 by The American Association for Thoracic Surgery

https://doi.org/10.1016/j.jtcvs.2019.08.003
}

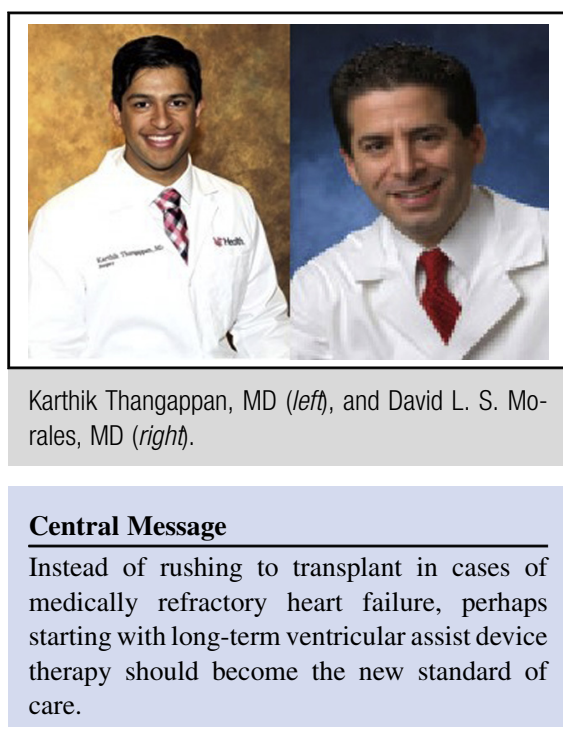

See Article page 1438 .
The article in this issue of the Journal by Adachi ${ }^{1}$ explores the current and changing state of affairs and mindset of pediatric ventricular assist device (VAD) therapy. Pediatric VADs have typically been used as inpatient "bridges" to the "destination" of transplantation. This is in contrast to the adult population, in which VAD therapy is often longterm, possibly permanent, and managed in the outpatient setting. In the adult VAD world, the younger patient is believed to have a higher potential for cardiac recovery; however, recovery from chronic heart failure (not myocarditis or graft rejection) is something not really pursued in the pediatric field. The fact that the vast majority of children requiring VAD support for chronic heart failure are listed for transplant as soon as feasible illustrates this. In certain pediatric centers, however, VAD therapy is being used to treat hospitalized patients with medically resistant heart failure or those who are outpatients who are not transplant candidates. Once the patient is in stable condition on VAD support, decisions about whether transplant or longterm therapy is preferable are being made, recognizing that this is a fluid state that can change with time. The predetermination of the patient's destiny before implantation of an intracorporeal continuous-flow VAD should no longer be necessary.

There are, of course, downsides (ie, adverse events) associated with VADs, which result in the hesitancy to adopt this mindset of long-term therapy as the standard of care. As the technology and field mature, however, morbidity profiles continue to decrease, and we must remember that cardiac graft expectancy is 15 to 20 years, with retransplantation graft expectancy being worse. ${ }^{2}$ The latter fact encourages us to explore pretransplant long-term VAD therapy to delay transplantation and potentially increase overall life expectancy. Waiting to list a VAD-supported outpatient provides an opportunity even to eliminate the need for transplantation by allowing more time for myocardial recovery. ${ }^{3}$ As technology improves and VADs become modular, however, the idea that VADs can be exchanged easily without a major cardiac surgery may result in cardiac transplantation becoming the exception, not the norm, for treating endstage heart failure in kids. Our institution has been practicing long-term therapy for some time, and we have demonstrated its benefits with HeartMate II (Abbott Laboratories, Abbott Park, Ill), HeartWare (Medtronic, Inc, HeartWare Division, Framingham, Mass), and more recently the HeartMate 3 (Abbott Laboratories) devices as long-term VAD therapy in a variety of patients with congenital heart disease (after Mustard procedure, Fontan circulation) and Duchenne muscular dystrophy $(n=6)$. This seems reasonable in light of the most recent data demonstrating that the 2-year survival for patients with a HeartMate 3 is equal to that of patients who have undergone heart transplantation. The development of smaller devices with better morbidity profiles will further encourage the paradigm shift of managing pediatric VADs. ${ }^{4}$

In conclusion, Adachi ${ }^{1}$ does an excellent job illustrating why long-term VAD support is and should be gaining clinical momentum and why the terms "bridge" and "destination" therapy may soon become obsolete. "Yes, we are there," because many of us in the field now routinely 
consider pediatric and congenital patients for long-term VAD therapy.

\section{References}

1. Adachi I. Pediatric ventricular assist device support as a permanent therapy: clinical reality. J Thorac Cardiovasc Surg. 2019;158:1438-41.
2. Kirklin JK, Carlo WF, Pearce FB. Current expectations for cardiac transplantation in patients with congenital heart disease. World J Pediatr Congenit Heart Surg. 2016;7:685-95.

3. Sandica E, Knyphausen EZ, Blanz U, Röfe D, Morshuis M. Safety of long-term mechanical support with Berlin heart EXCOR in pediatric patients. World J Pediatr Congenit Heart Surg. 2012:3:72-6.

4. Adachi I. Continuous-flow ventricular assist device support in children: a paradigm change. J Thorac Cardiovasc Surg. 2017;154:1358-61. 